\title{
El proceso de convertirse en un adolescente: Juan, pero no Don Juan ${ }^{1}$
}

\author{
Isabel Duarte Cunha² \\ IARPP, Lisboa
}

\begin{abstract}
En este trabajo la autora se inscribe en referencias teóricas que permiten realizar un nuevo enfoque en la lectura y comprensión del proceso de convertirse en un adolescente, en particular la teoría del pensamiento y modelo de las transformaciones que, junto con la analogía "construir en la oscuridad", permitió clarificar los movimientos en construcción durante este periodo de desarrollo.

El arte es por excelencia un lugar privilegiado para la expresión de los procesos mentales inconscientes, por lo que el clásico de la literatura española "Don Juan Tenorio" sirvió de base para la presentación de este trabajo psicoterapéutico realizado con un adolescente de 17 años, en el que fue posible observar las transformaciones inherentes al convertirse, permitiendo comprender la importancia de la dinámica relacional en su función de comunicación y simbolización.
\end{abstract}

Palabras clave: adolescencia, transformación, co-construcción, inconsciente, intersubjetividad.

In this work the author uses the theoretical frameworks that enable to perform a new approach to reading and understanding the process of becoming an adolescent, particularly the theory of thought and the model of transformations that, together with the analogy "build into the dark", allowed to explain the movements that are under construction during this period of development.

The art is for excellence a privileged place for the expression of unconscious mental processes, so the classic of the Spanish literature, Don Juan, was used as basis for the presentation of the psychotherapeutic work conducted with a 17-year-old adolescent, in which it was possible to observe the changes inherent to becoming, allowing us to understand the importance of relational dynamics, at its function of communication and symbolization.

Key Words: adolescence, transformation, co-construction, unconscious, intersubjectivity. English Title: The process of becoming a teenager: Juan, but not Don Juan

\section{Cita bibliográfica / Reference citation:}

Duarte, Isabel. (2017). El proceso de convertirse en un adolescente: Juan, pero no Don Juan. Clínica e Investigación Relacional, 11 (3): 546-553. [ISSN 1988-2939] [Recuperado de www.ceir.info ] DOI: 10.21110/19882939.2017.110306

\footnotetext{
${ }^{1}$ Comunicación presentada en la VII Reunión Anual IARPP-E, con el tema: El inconsciente relacional en lo individual y lo social, realizada en Barcelona 31 Marzo y 1 Abril 2017.

2 Doctora en Psicología Clínica, ISPA-IU. Miembro de IARPP International y de IARPP España. Práctica clínica privada en consultorio y en instituciones privadas. Alameda D. Afonso Henriques 27, 1. ${ }^{\circ}$ Dto., 1900-180 Lisboa isabelmgdc@gmail.com
}

CelR Vol. 11 (3) - Octubre 2017 ISSN 1988-2939 - www.ceir.info

(c) Derechos reservados/Copyright de Clínica e investigación Relacional y los autores. Prohibida la reproducción total o parcial sin autorización expresa. Este material es para uso científico y profesional exclusivamente y puede contener información clínica sensible. Los editores no se responsabilizan de los contenidos de los autores. Dirigir las consultas sobre derechos y autorizaciones a ceir@psicoterapiarelacional.es 
La adolescencia es un período de desarrollo durante el cual ocurren importantes transformaciones, que están relacionadas con el deseo de llegar a Ser y el no Ser aún, un camino de descubrimiento e integración que enlaza la niñez con la edad adulta. A lo largo de los años muchos han sido los estudios realizados sobre la adolescencia, verificando un aumento progresivo de los marcos teóricos.

En los modelos clásicos, la adolescencia se describe basada en la formación de los procesos de identidad e identificación, en los cuales existe la posibilidad de realizar opciones que dan forma a una nueva identidad y a una nueva representación del Yo, una dinámica que sólo es posible en la relación con el Otro(s) (Jeammet, 1980).

Propongo reflexionar sobre la adolescencia con inscripción en los nuevos enfoques teóricos, sobre todo, en los modelos que derivan de la teoría de las relaciones de objeto, en particular, la teoría del pensamiento y el modelo de las transformaciones de Bion (1982), ya que nos permiten describir y comprender las transformaciones que tienen lugar entre el comienzo y el final de este período de desarrollo, y que se presenta como un activo para mi práctica clínica, ya que permiten acceder a la circularidad del funcionamiento psíquico, basado en una dinámica co-constructiva.

\section{Construyendo en la oscuridad...}

El inconsciente es la piedra angular que permite la comprensión de los procesos mentales. Explicar la actividad de la conciencia, sin entender el dinámico inconsciente, es como tratar de comprender el movimiento a que un objeto está sometido, sin hacer ninguna referencia al objeto. Freud (1953) describe que fue obligado a "construir un camino en la oscuridad" creando una teoría metodológica que permite pensar el funcionamiento psicológico basado en la premisa de que la certeza y la evidencia son criterios importantes que dan lugar a una adaptación metodológica compleja e intensa.

La adolescencia se caracteriza por un proceso dinámico y creativo durante el cual están presentes una serie continua de transformaciones psíquicas que pueden ser pensadas utilizando la analogía de "construir en la oscuridad" (Caper, 2009), ya que este periodo de desarrollo, debe entenderse como un "proceso de transformación" (Braconnier, 1985) permitiéndonos acceder a la esencia del convertirse, debido a la existencia de procesos que ya están formados mientras otros aún están en desarrollo, verificándose una continuidad durante la transición de unos a otros, oscilando entre movimientos que van de la desidealización a la idealización y de la ruptura a la integración, construyendo y renovando nuevas fronteras del Yo y del Otro. 
Están presentes movimientos que oscilan en una alternancia entre las posiciones activas donde domina la afirmación del Yo - y las pasivas - marcadas por la retracción, cerrando el Otro. El modelo de las transformaciones es el que mejor explica la relación de encuentro y comunicación entre el sujeto y el objeto, y viceversa, entre el interno y el externo, el pasado y el presente, en una (re)creación de nuevos objetos con nuevas características y cualidades (Bion, 1982). Cuando se une la noción de "objeto transformacional", basado en que, ahora es posible representar la relación con un objeto, simbolizando la experiencia de la transformación (Bollas, 1989).

Sin embargo, el adolescente hoy no es el mismo que mañana, lo que plantea la necesidad de "aprender con la experiencia" (Bion, 1991), integrando no sólo lo vivido y experimentado, sino también revelando y (re)significando lo desconocido, es decir, los movimientos inconscientes de sí mismo que se manifiestan en la dinámica social, en la sociedad actual, donde la necesidad de procesar información es un imperativo que se produce a una velocidad vertiginosa.

En este sentido, es crucial la creación de un espacio de transformación, en el que es posible crear, (re)creando nuevos objetos y objetivos, lo cual sólo es posible a través de una relación intra e inter-subjetiva, un espacio de co-construcción, esencial para el desarrollo del Yo en la relación con el Otro(s) (Brown, 2011). El campo, en su dimensión clínica, es un espacio privilegiado para la revelación de esta dinámica, permitiéndonos acceder al proceso inconsciente de transformación en curso, donde son experimentadas emociones que aún no pueden ser representadas (Ferro, 2002).

En el teatro, se levanta el telón y los personajes llegan a la escena. La audiencia en la oscuridad, observa la producción artística, realizada con la función de comunicar, de revelar un proceso de creación. Al comienzo, el director de teatro puede no tener este trabajo completamente claro, pero la obra va emergiendo, teniendo como resultado la obra puesta en escena, reveladora de su visión, de su conocimiento (Caper, 2009). El arte en general y la literatura en particular, han sido a lo largo de los años una forma de expresión de los procesos psíquicos inconscientes. En la presentación clínica que sigue, me he inspirado en un clásico de la literatura española, Don Juan Tenorio, para ilustrar las diferentes partes presentes en el proceso de convertirse, en el que la lectura y la (re)significación del inconsciente, fueron fundamentales para la estructuración de los procesos de identidad y de identificación, es decir, para la consolidación de un Yo que piensa y se relaciona con lo(s) Otro(s). 


\section{Se abre el telón, empieza la pieza: Juan, pero no Don Juan.}

\section{Acto I - Cholo}

Juan es un adolescente de 17 años, a quien mi contacto fue dado para la realización de una psicoterapia por su lengua materna, el castellano, ya que se encuentra estudiando $2^{\circ}$ de Bachillerato en Portugal, en un colegio conceptuado de lengua inglesa y solamente habla estos idiomas. Viene después de haber tenido una crisis psicótica y de haber estado hospitalizado durante un mes, en sus vacaciones en el verano.

Alto y delgado, con los hombros encorvados sobre sí mismo, de piel morena y ojos verdes, con una mirada dispersa, es como Juan se presenta en la primera sesión. Un extraño en una tierra extraña, oriundo de Colombia, donde vivió hasta hace 2 años, cuando llegó a Portugal debido a que su madre ha sido enviada para trabajar por un período de 4 años. Sus orígenes son motivo de burla ("teasing") por parte de sus colegas, que procuran bromear sobre la cocaína, ponerle en ridículo y haciéndole sentir como un marginal, un "cholo", llevándole a un aislamiento, refugiándose en el uso de las redes sociales y ver pornografía, una práctica corriente en el grupo de pares.

Juan describe el brote psicótico que tuvo como si fuera su DNI: "He tenido un brote psicótico hace dos meses, estaba muy excitado, sexualmente excitado, con la cabeza muy aturdida, muchos pensamientos... pensamientos sexuales". Ante la imposibilidad de pensar la relación, Juan se queda atascado en una lógica donde dominan las incertidumbres y las dudas, buscando apropiarse de los afectos, como si fueran objetos que en verdad no permanecían, tal como en la pornografía, sólo quedaban las imágenes, desprovistas de sentido y significado.

Me quedé de inmediato con la imagen de un adolescente perdido, incapaz de dar sentido y significado a lo nuevo y desconocido que surgía en su proceso de convertirse en un adolescente, en un país también desconocido, con costumbres tan distintas a las que estaba acostumbrado. Los ambientes de fiesta y diversión del pasado entre amigos con los que le gustaba salir a pasarlo bien y tomarse unas cervezas dan ahora lugar a un aislamiento y una retractación, a un alejamiento de la realidad, percibida como amenazadora y peligrosa.

Como en el final del primer acto de Don Juan Tenorio, se hizo la apuesta, hecha por el vínculo relacional presente en el encuentro terapéutico. Sabíamos desde el principio que trabajaríamos por un tiempo definido, el año escolar, porque después Juan volvería a Colombia de vacaciones y tal vez empezar una carrera universitaria. 


\section{Acto II - Destreza}

Las fuertes divisiones presentes en el funcionamiento psíquico de Juan me llevaron desde un primer momento a adoptar una posición más activa y explícita con el fin de permitir una mejor estructuración psíquica (Wachtel, 2014).

La destreza en gestionar la técnica fue fundamental para que, sesión tras sesión, consiguiéramos pensar en los temas presentados por Juan, siempre anclados en una realidad social: el capitalismo, la ley de la oferta y la demanda en los mercados internacionales, el cambio de divisas... material que en su inconsciente individual está relacionado con el poder y la riqueza de su mundo interno, para la comunicación entre lo interno y externo, para las dificultades en los intercambios inherentes a las relaciones interpersonales.

La familia de Juan se destruyó en este contexto. Su madre, una persona muy influyente y con una profesión muy exigente que la obliga a estar fuera de su país durante largos períodos de tiempo, no se rinde ante el dolor y busca activamente en encontrar soluciones para su único hijo. El padre, bastante mayor que la madre, con la cual ha contraído su segundo matrimonio, es una persona muy sencilla y afectiva, que muestra preocupación por el desarrollo y futuro de su hijo más joven, ya que tiene dos hijos mayores de su primer matrimonio.

La madre de Juan está siempre muy angustiada, parece un amplificador, dificultando observar la realidad de una forma tranquila, por lo que queda demasiado distorsionada. Juan describe la relación con su madre como de apoyo y poca exigencia, pero distante a nivel emocional y sentimental. El padre demuestra creer en su hijo y presenta un mayor realismo en la interpretación de la realidad. Aunque Juan sienta su padre como más exigente, mantiene con él una mayor cercanía sentimental, compartiendo con él algunos gustos e intereses.

El proceso de convertirse involucra hacer nuevas identificaciones (Birraux, 1988). En la historia de Juan hay que destacar el papel de su abuelo materno, ya fallecido, un hombre con valor e integridad que le transmitía confianza, su modelo de identificación cuando piensa en su futuro profesional. Durante algunas sesiones se debate si será mejor, en términos de carrera, ir a una Universidad de su país o si debería estudiar en Inglaterra. ¿Cuál será el mejor curso? ¿Relaciones Internacionales o Economía Política? La fuerte ambivalencia que presenta está siempre acompañada del deseo de ser reconocido y valorado profesionalmente. 


\section{Acto III - Profanación}

A los tres meses de terapia Juan ya podía analizar sus actos profanos: ver pornografía acompañada de masturbación. Finalmente fue posible plantearse el episodio de rechazo que le marcó en el pasado: como Don Juan, se declaró a una chica que le gustaba y de la cual obtuvo una respuesta negativa. Este episodio lo vivió como una mezcla de rechazo y abandono, no había sido capaz de seducir a su doncella y, por lo tanto, se sentía sin crédito con las chicas, aún no era posible entender la complementariedad de la relación Yo-Otro.

La organización del mundo interno de Juan hace posible la elaboración de su bisexualidad psíquica, permitiendo la elección de la vía heterosexual después de mucha ambivalencia entre la homosexualidad y la heterosexualidad. La integración de su bisexualidad psíquica permitió la creación de un objeto interno más estable, que funcionó como un medio de acceso a su deseo, en la relación con el Otro (Birraux, 1988).

La progresiva diferenciación Yo-Otro permitió a Juan entender mejor la dinámica de su familia. Lo materno y lo paterno se presentaban como dos entidades muy distintas, difíciles de conciliar internamente, una vez que tenían una lógica antinatural, poniendo en duda el movimiento de la circularidad psíquica inherente en el proceso de convertirse en un adolescente, impidiendo así la adquisición del distanciamiento necesario para una mejor comprensión de los límites entre Uno y Otro y sesgar la identificación a un modelo masculino, con cualidades y atributos, facilitador de la construcción de un Yo suficientemente coherente y estable.

\section{Acto IV - El diablo a las puertas del cielo}

Al final, Don Juan tuvo que enfrentarse a sus fantasmas y sólo el amor que sentía por Doña Inés pudo salvarlo del infierno eterno (Molina, 2017). En el trabajo con Juan, no cabe duda que fue el espacio terapéutico, contenedor, transformador y (re)significador, lo que permitió el desarrollo de una capacidad relacional, una nueva mirada a lo vivido y sentido, en una cercanía emocional que permitió el descubrimiento: las añoranzas de casa, la curiosidad por el mundo en general y para mí, como su terapeuta, en particular. Ahora los temas eran otros, hablaba sobre los grandes temas de la literatura clásica, el amor, la traición, el odio...

Al final de la terapia, Juan estaba más seguro de su identidad, su lugar entre sus compañeros y familiares, podría integrar la dimensión afectiva en su relación con el Otro(s). El trabajo que llevamos a cabo permaneció con él más allá del setting, siendo visible en las diversas experiencias de su vida (Wachtel, 2014). Los signos físicos de cambio eran evidentes, la barba 
que cubría su rostro, los músculos que le dieron un porte atlético, la mirada suave y dulce, la autenticidad de su afecto. ¡Juan era casi un Don Juan!

\section{Cae el telón. Las luces se encienden.}

Lo que más emociona en el trabajo con los adolescentes es el propio proceso de transformación, donde cada sesión es como subir al escenario por primera vez, actuando a la vez con lo conocido y desconocido, lo consciente e inconsciente, lo viejo y lo nuevo, conectados y (re)creados en una escena que emerge de la "oscuridad" del Yo.

El espacio psicoterapéutico fue un lugar privilegiado para la experiencia directa de la relación, promoviendo una experiencia emocional correctiva. El desarrollo de la relación por la comunicación intra e inter-psíquica, favoreciendo la toma de consciencia de los procesos inconscientes, favoreciendo los procesos de transformación y potenciando el crecimiento mental (Ferro, 2009). La lectura de los movimientos transfero-contratransferenciales fue fundamental, junto con la comprensión de lo que estaba sucediendo en el setting (Wachtel, 2014).

El principal reto con Juan fue potenciar la realización de nuevos cambios psíquicos al nivel del Yo, permitiéndole la construcción de su mapeo de identidad y suficientemente diferenciadoras de la relación Yo-Otro, en un movimiento progresivo hacia el crecimiento, es decir, transformaciones del conocimiento en la realidad última "O" (Cunha, 2016), la apoteosis del amor en Don Juan, convertida aquí en la autenticidad de Ser naturalmente Juan.

\section{REFERENCIAS}

Bion, W.R. (1982). As transformações. As mudanças do aprender para o crescer. Imago: Rio de Janeiro.

Bion, W.R. (1991). Atenção e Interpretação. O acesso científico à intuição em psicanálise e grupos. Rio de Janeiro: Imago Editora.

Birraux, A. (1988). Présentation du «Masculin». Adolescence, 6, (1), 5-16.

Bollas, C. (1989). L'objet Transformationnel. Revue Française de Psychanalyse, LIII, 1181-1199.

Braconnier, A. (1985). Ruptures et séparations. Adolescence, 3, 1. 5-19.

Brown, L. (2011). Intersubjective Processes and the Unconscious. An integration of Freudian, Kleinian and Bionian Perspectives. London: Routledge.

Caper, R. (2009). Building out into the dark. Theory and observation in science and psychoanalysis. London and New York: Routledge. 
Cunha, I.D. (2016). O Tornar-se Adolescente através do Rorschach. Tese de Doutoramento em Psicologia Clínica. Lisboa: ISPA-IU.

Ferro, A. (2002). The Work of the Negative. International Journal of Psycho-Analysis, 83, (4), 974-982.

Ferro, A. (2009). Mind Works. Technique and Creativity in Psychoanalysis. London: Routledge.

Freud, S. (1953). The Interpretation of Dreams - Vol. IV e V. The Standart Edition of the Complete Psychological Works of Sigmund Freud. London: The Hogarth Press and the Institute of PsychoAnalysis.

Jeammet, P. (1980). Réalité externe et réalité interne importance et spécificité de leur articulation a I'adolescence. Revue Française de Psychanalyse. 3-4, 481-521.

Molina, T. de. (2017). Don Juan. Madrid: Penguin Clasicos.

Wachtel, P. (2014). An Integrative Relational Point of View. Therapeutic Relationship. Relational Foundations of Psychotherapy. 51(3). pp. 342-349.

Original recibido con fecha: 22-4-2017 Revisado: 30-8-2017 Aceptado: 30/09/2017 